\title{
Impact of Obesity and Its Associated Comorbid Conditions on COVID-19 Presentation
}

\author{
Osama Mehanna ${ }^{1,2}$ \\ Ahmad El Askary 3,4 \\ Ebtesam $\mathrm{Ali}^{5}$ \\ Basem El Esawy $y^{3,6}$ \\ Tamer FathAlla ${ }^{7}$ \\ Amal F Gharib ${ }^{3,8}$
}

'Department of Medical Physiology, College of Medicine, Taif University, Taif 21944, Saudi Arabia; ${ }^{2}$ Department of Medical Physiology, Faculty of Medicine, Al-Azhar University, New Damietta, Egypt; ${ }^{3}$ Department of Clinical Laboratory Sciences, College of Applied Medical Sciences, Taif University, Taif 21944, Saudi Arabia; ${ }^{4}$ Department of Medical Biochemistry, Faculty of Medicine, Al-Azhar University, New Damietta, Egypt; ${ }^{5}$ Directorate of Health Affairs, Gharbia Governorate, Ministry of Health and Population, Cairo, Egypt; ${ }^{6}$ Department of Pathology, Faculty of Medicine, Mansoura University, Al Mansurah, Egypt; ${ }^{7}$ Department of Anaesthesia and ICU, Faculty of Medicine, Al-Azhar University, New Damietta, Egypt; ${ }^{8}$ Department of Medical Biochemistry, Faculty of Medicine, Zagazig University, Zagazig, Egypt

Correspondence: Osama Mehanna Emaildr587@yahoo.com
This article was published in the following Dove Press journal: Diabetes, Metabolic Syndrome and Obesity: Targets and Therapy

Background: There is great variability in clinical presentation of COVID-19 worldwide. The current study evaluated the impact of obesity and its related complications on the course of COVID-19 in Egyptian patients.

Methods: We included 230 COVID-19 Egyptian patients from Tanta City. According to their body-mass index (BMI), patient were divided into three groups: normal weight (BMI $<25 \mathrm{~kg}$ / $\mathrm{m}^{2}$ ), overweight $\left(\right.$ BMI $\left.>25-<30 \mathrm{~kg} / \mathrm{m}^{2}\right)$, and obese $\left(\mathrm{BMI} \geq 30 \mathrm{~kg} / \mathrm{m}^{2}\right)$. Patients' glycemic status, lipid profile, and serum levels of acute-phase reactants were assessed. The number of patients receiving intensive care and the number of deaths in each group were counted.

Results: Mean values of random blood sugar, serum cholesterol, triglycerides, serum ferritin, erythrocyte-sedimentation rate, LDH, CRP, D-dimer levels, and blood pressure were significantly higher in obese patients $(165.6,129.5,105,1,873,26,403,56.45$, 977.16 and 142/87, respectively) than in normal-weight $(97.2,103.5,70.4,479,17.4,252$, 23.2, 612.4, and 118.6/76.8, respectively) and overweight patients (111.4, 106.3, 78.13, 491.3, 19.8, 269.27, 25.42, 618.4, and 120.3/79.3, respectively). Lymphopenia was also significantly predominant in the obese group. Multivariate logistic regression analysis revealed that elevated serum triglycerides, total cholesterol, low density-lipoprotein cholesterol, blood pressure, ferritin, CRP, and low relative lymphocyte count were significant risk factors in obese COVID-19 patients.

Conclusion: Obesity and its related complications increase the risk of presenting a more severe form of COVID-19 in Egyptian patients.

Keywords: obesity, COVID-19, Egyptian

\section{Introduction}

On March 11, 2020, the World Health Organization declaredCOVID-19 a global pandemic. COVID-19 represents a great challenge to health-care systems, due to its rapid spread, serious complications, and high fatality rate. ${ }^{1}$ The presentation of COVID-19 patients varies widely, andmany studies have evaluated risk factors (age, sex, comorbidities) that may be related to COVID-19 complications and deaths. Studies to date have shown a worldwide predominance of elderly males, as well as those with cardiovascular diseases, in adverse COVID-19 outcomes.

With its rising prevalence, obesity is a major risk factor in many noncommunicable diseases. ${ }^{4}$ People with obesity in general are more likely to develop serious illness and need more hospitalization or ICU admission. ${ }^{5}$

A recent meta-analysis provided evidence that obesity-associated complications are important associated risk factors for severe acute respiratory syndrome coronavirus 2 (SARS-CoV2) infection. ${ }^{6}$ 
Among obese patients, excess adipocytes may enhance immunological and inflammatory alterations. ${ }^{7}$ Increased mass of adipose tissue is a well known contributing factor in proinflammatory cascades. ${ }^{8}$

SARS-CoV2, which causes the current COVID-19 global pandemic, has high affinity for human ACE2. ${ }^{9-11}$ ACE2 receptors show increased gene expression in adipose tissue. ${ }^{1}$ As such, excess body fat consequently increases ACE2 receptors and may increase the risk of SARS-CoV2 infection and developing a severe form of COVID-19. ${ }^{12,13}$

The aim of this study was to assess the effect of increased body weight and its consequences on blood pressure, blood glucose, triglycerides, and cholesterol in COVID-19 complications and case-fatality rates (deaths divided by confirmed cases) in Egyptian patients from Tanta, Gharbia Governorate, Egypt.

\section{Methods}

\section{Sample}

This study was conducted on COVID-19 patients who were home-isolated. Procedures were performed after prior approval by the Ethics Review Committee of $\mathrm{Al}$ Azhar University Faculty of Medicine and in accordance to the principles expressed in the Declaration of Helsinki. Informed consent was obtained from all patients before participating in the study. All patients were recruited from Tanta during the COVID-19 pandemic. The study was performed during from June 2020 to July 2020. A total of 230 COVID-19 positive patients were included. Diagnosis of COVID-19 was established by positive PCR, and further assessment was done by chest CT. Blood samples were collected from patients for laboratory investigations at 5-7 days after the appearance of symptoms. According to their BMI, patients were divided into three groups:normal weight (30 patients with BMI $<25 \mathrm{~kg}$ / $\mathrm{m}^{2}$ ), overweight (58 patients with BMI $>-25<30 \mathrm{~kg} / \mathrm{m}^{2}$ ), and obese (142 patients with BMI $\geq 30 \mathrm{~kg} / \mathrm{m}^{2}$ ). Patient were aged $20-52$ years.

No statistically significant differences were recorded among the studied groups in mean age $(44.2 \pm 13.8$ years in normal-weight group, 44.6 \pm 17.2 in overweight group, and $46.8 \pm 11.2$ in obese group). Sex distribution showed no statistically significant differences either (19 males [63\%] and eleven females [37\%] in normal-weight group, 32 males [55\%] and 26 females [45\%] in overweight group, and 75 males [53\%] males and 49 females [47\%] in obese group). We followed up with patients during the study. All patients were in the early stage of the disease, approximately the first week after appearance of symptoms, when enrolled in the study. Patients were receiving the same treatment protocol (oseltamivir, azithromycin, hydroxychloroquine, and paracetamol), in addition to regular treatment for diabetes and hypertension.

The number of patients admitted to ICUs and the number of deaths in each group were counted. Random blood sugar, lipid profile, and systolic and diastolic blood pressure were measured for all patients. In addition, acutephase reactants (serum ferritin, erythrocyte-sedimentation rate [ESR], LDH, CRP, D-dimer test, and relative lymphocyte count) were evaluated in all patients to assess the severity of the disease.

\section{Laboratory Analysis}

Serum glucose, total cholesterol, triglycerides, high densitylipoprotein cholesterol, and low density-lipoprotein cholesterol were determined by enzymatic methods using commercially available kits according to instructions. Serum CRP was measured with an autoanalyzer (Toshiba, Tokyo, Japan) and immunoturbidimetric analysis (CRP II Latex X2; Denka Seiken, Tokyo, Japan). Serum-ferritin levels were evaluated using an ELISA kit (RCD012R, BioVendor). Estimation of serum LDH was performed using an LDH-activity assay kit, (7D69-20, Abbott Diagnostics). Plasma D-dimer was measured with an ELISA kit (NB 110-8376, Novus Biologicals). Lymphocyte count were performed with an autohematology analyzer (Sysmex BC 3000).

\section{Statistical Analysis}

Pooled data and results are presented as means \pm SD and were analyzed for statistical significance with SPSS 22. One way ANOVA with post hoc tests were used for calculation of significance between quantitative parameters, and $?^{2}$ tests to compare proportions between qualitative parameters. Results were considered significant at $P<0.05$. Alogistic regression analysis model was used for studied parameters to analyze their relation to obesity.

\section{Results}

\section{Weight-Disaggregated Data of Studied} Patients

Figure 1 shows that of the 230 COVID-19 patients, 142 (61.7\%) were obese, 58 (25.2\%) overweight, and 30 (13\%) of normal weight. The number of patients with diabetes was $43(30.28 \%)$ in the obese group and eleven (18.9\%) and four $(13.3 \%)$ in the overweight and normal-weight groups, 


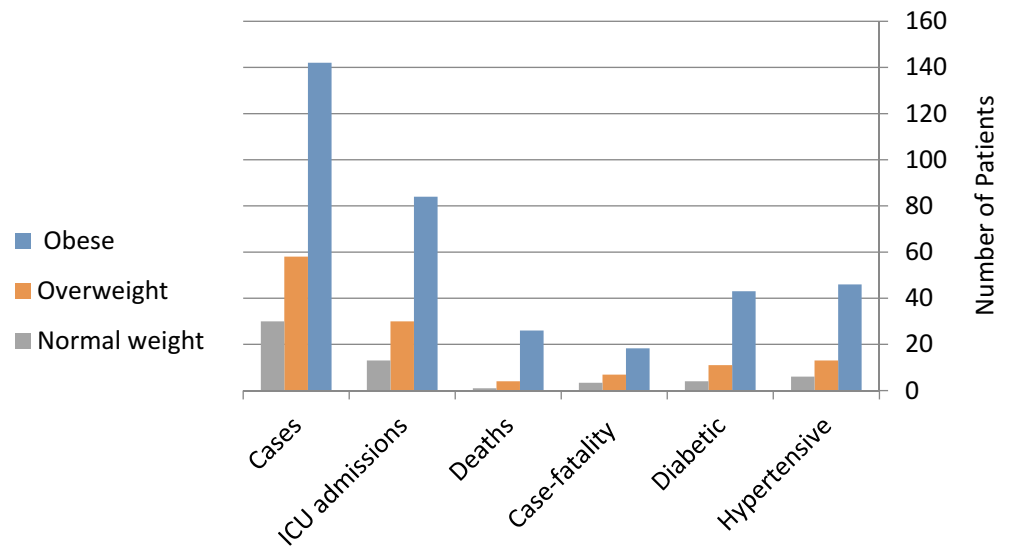

Figure I Weight-disaggregated data of patients.

respectively. Regarding blood pressure, there were 46 hypertensive patients (32.4\%) in the obese group and 13 (22.4\%) and $6(20 \%)$ in the overweight and normal-weight groups, respectively. Of the 142 COVID-19 obese patients, 84 (59.15\%) were admitted to ICUs, where $26(18.3 \%)$ died and $116(81.7 \%)$ were discharged, while of the 58 overweight and 30 normal-weight COVID-19 patients, 30 (51.7\%) and $13(43.3 \%)$ were admitted to ICUs, where four (6.89\%) and 1 (3.33\%) died and 54 (93\%) and $29(96.6 \%)$ were discharged in the overweight and normal-weight groups, respectively. All patients that died were diabetic and hypertensive.
Hospitalization and ICU admission due to COVID-19 was after an average of 2-3 weeks from the beginning of symptoms. All patients received mechanical ventilation and $\mathrm{O}_{2}$. All the aforementioned parameters were significantly higher in the obese group than the normal-weight and overweight groups.

\section{Obesity-Related Characteristics in COVID-19 Patients}

Table 1 shows obesity-associated characteristics in studied groups, where the results revealed normal levels of

Table I Demographic and obesity-associated characteristics in studied groups

\begin{tabular}{|c|c|c|c|c|c|}
\hline & \multirow{2}{*}{$\begin{array}{l}\text { Normal Weight } \\
\left(\mathrm{BMI}<25 \mathrm{~kg} / \mathrm{m}^{2}\right) \text {, } \\
\mathrm{n}=30\end{array}$} & \multirow{2}{*}{$\begin{array}{l}\text { Overweight } \\
\left(\text { BMI }>25-<30 \mathrm{~kg} / \mathrm{m}^{2}\right) \text {, } \\
\mathrm{n}=58\end{array}$} & \multirow{2}{*}{$\begin{array}{l}\text { Obese } \\
\left(B M I \geq 30 \mathrm{~kg} / \mathrm{m}^{2}\right), \\
n=142\end{array}$} & \multicolumn{2}{|l|}{ ANOVA } \\
\hline & & & & $\boldsymbol{F}$ & $P$ \\
\hline Age (years) & $44.2 \pm 13.8$ & $44.6 \pm 17.2$ & $46.8 \pm 11.2$ & 0.849 & 0.429 \\
\hline Sex (male/female) & $\begin{array}{l}19 / 11 \\
63 \% / 37 \%\end{array}$ & $\begin{array}{l}32 / 26 \\
55 \% / 45 \%\end{array}$ & $\begin{array}{l}75 / 49 \\
53 \% / 47 \%\end{array}$ & $?^{2}=0.683$ & 0.711 \\
\hline Random BG (mg/dL) & $97.2 \pm 6.3$ & $111.4 \pm 8.1^{\mathrm{a}}$ & $165.6 \pm 13^{\mathrm{a}, \mathrm{b}}$ & 764.209 & $<0.001 *$ \\
\hline Serum triglycerides (mmol/L) & $70.4 \pm 4.2$ & $78.13 \pm 4.5^{\mathrm{a}}$ & $105.4 \pm 14.3^{\mathrm{a}, \mathrm{b}}$ & 185.218 & $<0.001 *$ \\
\hline Serum cholesterol (mmol/L) & $103.5 \pm 5.7$ & $106.3 \pm 6.3$ & $129 \pm 5.5^{\mathrm{a}, \mathrm{b}}$ & 464.268 & $<0.001 *$ \\
\hline HDL cholesterol (mmol/L) & $49.4 \pm 3.1$ & $47.9 \pm 3.2$ & $41.9 \pm 4.2^{\mathrm{a}, \mathrm{b}}$ & 79.560 & $<0.001 *$ \\
\hline LDL cholesterol (mmol/L) & $57.6 \pm 8.3$ & $59.7 \pm 8.4$ & $87.11 \pm 2.6^{\mathrm{a}, \mathrm{b}}$ & 701.003 & $<0.001 *$ \\
\hline Systolic BP (mmHg) & $118.6 \pm 9.4$ & $120.3 \pm 10.1$ & $142 \pm 14.6^{\mathrm{a}, \mathrm{b}}$ & 79.813 & $<0.00 I^{*}$ \\
\hline Diastolic BP (mmHg) & $76.8 \pm 6.2$ & $79.3 \pm 7.4$ & $87 \pm 9.8^{\mathrm{a}, \mathrm{b}}$ & 30.189 & $<0.001 *$ \\
\hline BMI $\left(\mathrm{kg} / \mathrm{m}^{2}\right)$ & $21.4 \pm 3.2$ & $27.8 \pm 4.3^{\mathrm{a}}$ & $34.1 \pm 5.1^{\mathrm{a}, \mathrm{b}}$ & 106.719 & $<0.001 *$ \\
\hline
\end{tabular}

Notes: Data expressed as means \pm SD, One-way ANOVA with post hoc test used for calculation of significance. $P<0.05$ was considered significant. ${ }^{a}$ Significantly different from normal-weight group; 'Significantly different from overweight group. *Statistically significant difference.

Abbreviations: BMI, body-mass index; BG, blood glucose; HDL, high-density lipoprotein; LDL, low-density lipoprotein; BP, blood pressure. 
Table 2 Laboratory characteristics associated with COVID-19 severity in studied groups

\begin{tabular}{|c|c|c|c|c|c|}
\hline & \multirow{2}{*}{$\begin{array}{l}\text { Normal weight } \\
\left(\mathrm{BMI}<25 \mathrm{~kg} / \mathrm{m}^{2}\right) \text {, } \\
\mathrm{n}=30\end{array}$} & \multirow{2}{*}{$\begin{array}{l}\text { Overweight } \\
\left(B M I>25-<30 \mathrm{~kg} / \mathrm{m}^{2}\right) \text {, } \\
n=58\end{array}$} & \multirow{2}{*}{$\begin{array}{l}\text { Obese } \\
\left(\text { BMI } \geq 30 \mathrm{~kg} / \mathrm{m}^{2}\right), \\
n=142\end{array}$} & \multicolumn{2}{|l|}{ ANOVA } \\
\hline & & & & $\boldsymbol{F}$ & $P$ \\
\hline Ferritin (ng/mL) & $479.4 \pm 59$ & $491.3 \pm 61$ & $|, 873 \pm| 38^{\mathrm{a}, \mathrm{b}}$ & $3,949.63$ & $<0.001^{*}$ \\
\hline ESR in first hour $(\mathrm{mm})$ & $17.5 \pm 7.4$ & $19.8 \pm 7.1$ & $26 \pm 4.26^{\mathrm{a}, \mathrm{b}}$ & 44.537 & $<0.00 I^{*}$ \\
\hline Lymphocytes (\%) & $16.8 \pm 2.15$ & $18 \pm 2.35$ & $9 \pm 3.09^{\mathrm{a}, \mathrm{b}}$ & 255.327 & $<0.001^{*}$ \\
\hline LDH (U/L) & $252.31 \pm 33.11$ & $269.27 \pm 30.21$ & $403.4 \pm 54.16^{\mathrm{a}, \mathrm{b}}$ & 243.978 & $<0.001 *$ \\
\hline $\mathrm{CRP}(\mathrm{mg} / \mathrm{L})$ & $23.2 \pm 3.01$ & $25.42 \pm 3.13$ & $56.45 \pm 5.28^{\mathrm{a}, \mathrm{b}}$ & $1,3 \mid 3.485$ & $<0.001^{*}$ \\
\hline D-dimer (ng/mL) & $612.4 \pm 24.6$ & $618.4 \pm 25.9$ & $977.16 \pm 33^{\mathrm{a}, \mathrm{b}}$ & $3,835.195$ & $<0.001^{*}$ \\
\hline
\end{tabular}

Notes: Data expressed as means \pm SD. One-way ANOVA with post hoc test used for calculation of significance. $P<0.05$ was considered significant. ${ }^{a}$ Significantly different from normal-weight group; 'significantly different from overweight group. *Statistically significant difference.

Abbreviation: ESR, erythrocyte-sedimentation rate.

random blood sugar, serum total cholesterol, triglycerides, and blood pressure in the normal-weight and overweight groups. A significant increase was observed in levels of these among the obese group when compared to the overweight and normal-weight groups $(P<0.001)$. There were significant differences between the normal-weight and overweight groups regarding mean values of random blood glucose, triglycerides, and BMI, while the other parameters showed no significant difference.

\section{Impact of Obesity on Severity of COVID- 19}

Table 2 shows levels of acute-phase reactants in the groups, where the results revealed increased levels of serum ferritin, ESR, LDH, CRP, and D-dimer in COVID19 patients, with significant elevation observed in the obese group compared to the overweight and normalweight groups $(P<0.001)$. In addition, lymphocytes were reduced in all groups due to SARS-CoV2 infection, with a significant difference in the obese group when compared to the overweight and normal-weight groups, while there was no statistically significant difference when we compared the overweight and normal-weight groups.

\section{Logistic Regression Analysis}

Univariate and multivariate logistic regression analysis was performed to study the parameters included in the current research in relation to obesity. Table 3 showed that random blood glucose, serum triglycerides, total cholesterol, high density-lipoprotein cholesterol, low density-lipoprotein cholesterol, blood pressure, ferritin, ESR, lymphocytes, LDH, CRP, and D-dimer had a significant effect on predicting outcome of COVID-19 in obese patients on univariate analysis, while serum triglycerides, total cholesterol, low density-lipoproteincholesterol, blood pressure, ferritin, lymphocytes, and CRP were significant risk factors in obese COVID-19 patients on multivariate analysis.

\section{Discussion}

The pandemic of acute respiratory distress due to COVID19 caused by SARS-CoV2 showed great variation regarding factors related to the severity and fatality of this disease. $^{14,15}$

Of 230 patients included in the study, there were 142 obese, 58, overweight and 30 normal-weight patients (obese group ORO1.61; 95\% CI 1.17-2.23).)

The number of obese COVID-19 patients admitted to ICUs was double that of both overweight and normalweight groups (84 versus 43, respectively). The number of deaths and case-fatality ratio among obese COVID-19 patients were also significantly higher $(26,18.3 \%)$ than the overweight $(4,6.89 \%)$ and normal-weight groups (1, $3.33 \%$ ). These differences show a higher susceptibility of obese patients to develop complications and a greater need for acute care and ICU admission. Many studies have reported similar results to ours regarding susceptibility of obese COVID-19 patients to requiring special care and admission to the ICU. ${ }^{16-21}$

Our results of poor outcomes in obese COVID-19 patients are in agreement meta-analyses conducted by Hussain et al and Pranata et al. ${ }^{12,13}$

Mean values of risk factors for COVID-19 initiation and progression, ie, prevalence of diabetes, hypertension, high blood glucose, dyslipidemia, and high blood pressure, 
Table 3 Univariate and multivariate logistic regression analyses

\begin{tabular}{|c|c|c|c|c|c|c|c|c|}
\hline \multirow[b]{3}{*}{ Age } & \multicolumn{4}{|c|}{ Univariate analysis } & \multicolumn{4}{|c|}{ Multivariate analysis } \\
\hline & \multirow{2}{*}{$\begin{array}{l}\text { OR } \\
1.244\end{array}$} & \multicolumn{2}{|c|}{$95 \% \mathrm{Cl}$} & \multirow{2}{*}{$\begin{array}{l}P \\
0.947\end{array}$} & \multirow{2}{*}{$\begin{array}{c}\text { OR } \\
-\end{array}$} & \multicolumn{2}{|c|}{$95 \% \mathrm{Cl}$} & \multirow[t]{2}{*}{$P$} \\
\hline & & 1.129 & 1.371 & & & & & \\
\hline Sex & 1.306 & 1.185 & 1.439 & 0.995 & - & & & \\
\hline Random BG (mg/dL) & 1.528 & 1.387 & 1.684 & $0.039 *$ & - & & & \\
\hline Serum triglycerides (mmol/L) & 1.359 & 1.218 & 1.516 & $0.035^{*}$ & 1.203 & 1.078 & 1.342 & $0.048^{*}$ \\
\hline Serum cholesterol (mmol/L) & 1.570 & 1.217 & 2.024 & $0.023^{*}$ & 1.389 & 1.077 & 1.791 & $0.031 *$ \\
\hline HDL cholesterol (mmol/L) & 1.605 & 1.456 & 1.768 & $0.043^{*}$ & - & & & \\
\hline LDL cholesterol $(\mathrm{mmol} / \mathrm{L})$ & 1.285 & 1.224 & 1.349 & $0.029 *$ & 1.137 & 1.083 & 1.194 & $0.040 *$ \\
\hline Systolic BP (mmHg) & 0.414 & 0.167 & 1.027 & $0.016 *$ & 0.366 & 0.148 & 0.909 & $0.022 *$ \\
\hline Diastolic BP (mmHg) & 3.066 & 1.911 & 6.869 & $0.009 *$ & 2.713 & 1.691 & 6.079 & $0.013 *$ \\
\hline Ferritin (ng/mL) & 1.250 & 1.219 & 1.280 & $0.021 *$ & 1.106 & 1.079 & 1.133 & $0.029 *$ \\
\hline ESR first hour (mm) & 1.214 & 1.047 & 1.407 & $0.032 *$ & - & & & \\
\hline Lymphocytes (\%) & 2.348 & 1.376 & 4.004 & $0.012^{*}$ & 2.078 & 1.218 & 3.543 & $0.017^{*}$ \\
\hline LDH (U/L) & 0.739 & 0.487 & 1.122 & $0.044^{*}$ & - & & & \\
\hline CRP (mg/L) & 0.105 & 0.019 & 0.549 & $0.003 *$ & 0.093 & 0.017 & 0.486 & $0.004^{*}$ \\
\hline D-dimer (ng/mL) & 1.133 & 1.076 & 1.193 & $0.035^{*}$ & - & & & \\
\hline
\end{tabular}

Notes: Univariate and multivariate logistic regression analysis used for studied parameters in obese COVID-I9 patients. $P<0.05$ was considered significant. $*$ Significant difference.

Abbreviations: BG, blood glucose; HDL, high-density lipoprotein; LDL, low-density lipoprotein; BP, blood pressure; ESR, erythrocyte-sedimentation rate.

were significantly higher in the obese group than the overweight and normal-weight groups. In accordance with our results, Caussy et al reported that obese COVID-19 patients were more susceptible to developing severe complications. $^{22}$ These parameters are well known factors involved in alteration of the immune system in COVID-19 patients. Increased expression of ACE2 in adipose tissue may aggravate the presentation and condition of COVID19 patients, because ACE2 receptors are clearly recognized as the main SARS-CoV2 receptors. ${ }^{23-26}$

Acute-phase reactants related to severity of inflammation, ie, CRP, serum ferritin, D-dimer, ESR, and LDH, showed increased levels in the obese group compared to the overweight and normal-weight groups. These findings demonstrate an important outcome of obesity in terms of severity of inflammatory response in obese patients infected with COVID-19. We performed logistic regression analysis to determine significant risk factors in relation toobesity. Univariate logistic regression analysis showed that all studied laboratory parameters were significant $(P<0.05)$ in the obese group. Multivariate logistic regression analysis demonstrated that high levels of serum triglycerides, total cholesterol, low density-lipoprotein cholesterol, blood pressure, ferritin, and CRP and lowlymphocyte count were significant risk factors in obese COVID-19 patients.

In agreement with the results of our study, many studies have reported higher values for inflammatory markers in aggravated cases of pneumonia. ${ }^{7,8,27}$ The appropriate detection of patients susceptible to developing fulminant inflammatory responses plays a key role in the management of COVID-19 patients.

The presence of lymphopenia is a sensitive marker for the severity of COVID-19. The lymphopenia found in the obese group was significantly different from the overweight and normal-weight groups. These results were in agreement with results reported by Tan et al. ${ }^{28}$

We believe that modulation of inflammatory markers and inflammatory immunoresponse can be an important key in management of patients with obesity suffering from SARS-CoV2. The results of our study should guide preventive measures required for vulnerable groups against catching SARS-CoV2. A limitation of the present study 
was that treatment strategies were not included in the research. The study was conducted on a small number of patients, so we recommend further studies on large numbers of Egyptian patients with COVID-19 to explore the most suitable protocols for management of COVID-19 patients suffering from obesity.

In conclusion, this study demonstrated that obesity and its related comorbidities can increase the risk of presenting a more severe form of COVID-19 in Egyptian patients. Therefore, the study recommends the importance of raising awareness of obesity-prevention strategies and recommendations, such as limiting unhealthy foods, increasing physical activity, limiting television time, screen time, and other "sitting times" to increase resistance to SARS-COV2 complications.

\section{Data-Sharing Statement}

Data are available upon request.

\section{Ethics Approval and Consent to Participate}

Ethics approval was obtained from the Ethics Review Committee of Al Azhar University Faculty of Medicine (270-6/2020). Informed consent was obtained from all patients before participation in the study.

\section{Acknowledgment}

The authors would like to extend their sincere thanks for the financial support of Taif Univesrsity Researchers Supporting Project number (TURSP-2020/82), Taif University, Taif, Saudi Arabia.

\section{Disclosure}

All authors declare that they have no conflicts of interest for this work.

\section{References}

1. Bello-Chavolla O, Bahena-López JP, Antonio-Villa NE, et al. Predicting mortality due to SARS-CoV-2: a mechanistic score relating obesity and diabetes to COVID-19 outcomes in Mexico. J Clin Endocrinol Metab. 2020;105(8):2752-2761. doi:10.1210/clinem/ dgaa346

2. Gebhard C, Regitz-Zagrosek V, Neuhauser HK, et al. Impact of sex and gender on COVID-19 outcomes in Europe. Biol Sex Differ. 2020;11. doi:10.1186/s13293-020-00304-9

3. Wu C, Chen X, Cai Y, et al. Risk factors associated with acute respiratory distress syndrome and death in patients with coronavirus disease 2019 pneumonia in Wuhan, China. JAMA Intern Med. 2020;180:934. doi:10.1001/jamainternmed.2020.0994

4. Kopelman PG. Obesity as a medical problem. Nature. 2000;404 (6778):635-643. doi:10.1038/35007508
5. Frühbeck G, Toplak H, Woodward E, Yumuk V, Maislos M, Oppert JM; Executive Committee of the European Association for the Study of Obesity. Obesity: the gateway to ill health - an EASO position statement on a rising public health, clinical and scientific challenge in Europe. Obes Facts. 2013;6(2):117-120. doi:10.1159/000350627

6. Wang B, Li R, Lu Z, Huang Y. Does comorbidity increase the risk of patients with COVID-19: evidence from meta-analysis. Aging (Albany NY). 2020;12(7):6049-6057. doi:10.18632/aging.103000

7. Goossens GH. The metabolic phenotype in obesity: fat mass, body fat distribution, and adipose tissue function. Obes Facts. 2017;10 (3):207-215. doi:10.1159/000471488

8. Rosen ED, Spiegelman BM. What we talk about when we talk about fat. Cell. 2014;156(1-2):20-44. doi:10.1016/j.cell.2013.12.012

9. Al-Benna S. Association of high level gene expression of ACE2 in adipose tissue with mortality of COVID-19 infection in obese patients. Obesity Med. 2020;19:100283. doi:10.1016/j.obmed.2020.100283

10. Kassir R. Risk of COVID-19 for patients with obesity. Obes Rev. 2020;21(6):e13034). doi:10.1111/obr.13034

11. Bourgonje AR, Abdulle AE, Timens W, et al. Angiotensin-converting enzyme 2 (ACE2), SARS-CoV-2 and the pathophysiology of coronavirus disease 2019 (COVID-19). J Pathol. 2020;251(3):228-248. doi:10.1002/path.5471

12. Hussain A, Mahawar K, Xia Z, Yang W, El-Hasani S. Obesity and mortality of COVID-19. Obesity Res Clin Pract. 2020;14(4):295300. doi:10.1016/j.orcp.2020.07.002

13. Pranata R, Lim MA, Yonas E, et al. Body mass index and outcome in patients with COVID-19: a dose-response meta-analysis. Diabetes Metab. 2020;S1262-3636(20)30097-5. doi:10.1016/j.diabet.2020.07.005

14. Li X, Xu S, Yu M, et al. Risk factors for severity and mortality in adult COVID-19 inpatients in Wuhan. $J$ Allergy Clin Immunol. 2020;146:110-118. doi:10.1016/j.jaci.2020.04.006

15. Wu Z, McGoogan JM. Characteristics of and important lessons from the coronavirus disease 2019 (COVID-19) outbreak in China: summary of a report of 72314 cases from the Chinese Center for Disease Control and Prevention. JAMA. 2020;323(13):1239-1242. doi:10.1001/jama.2020.2648

16. Cariou B, Hadjadj S, Wargny M, et al. CORONADO investigators. Phenotypic characteristics and prognosis of inpatients with COVID19 and diabetes: the CORONADO study. Diabetologia. 2020;63 (8):1500-1515. doi:10.1007/s00125-020-05180-x

17. Busetto L, Bettini S, Fabris R, et al. Obesity and COVID-19: an Italian snapshot. Obesity (Silver Spring). 2020;28:1600-1605. doi: $10.1002 /$ oby. 22918

18. Simonnet A, Chetboun M, Poissy J, et al. High prevalence of obesity in severe acute respiratory syndrome coronavirus-2 (SARS-CoV-2) requiring invasive mechanical ventilation. Obesity (Silver Spring). 2020;28(7):1195-1199. doi:10.1002/oby.22831

19. Intensive Care National Audit \& Research Centre. Audit I. ICNARC Report on COVID-19 in Critical Care April 10 2020. London, UK: Intensive Care National Audit and Research Centre; 2020.

20. Lighter J, Phillips M, Hochman S, et al. Obesity in patients younger than 60years is a risk factor for Covid-19 hospital admission. Clin Infect Dis. 2020;71(15):896-897. doi:10.1093/cid/ciaa415

21. Goyal P, Choi JJ, Pinheiro LC, et al. Clinical characteristics of Covid19 in New York city. $N$ Engl J Med. 2020;382(24):2372-2374. doi:10.1056/NEJMc2010419

22. Caussy C, Pattou F, Wallet F, et al. Prevalence of obesity among adult inpatients with COVID-19 in France. Lancet Diabetes Endocrinol. 2020;8(7):562-564. doi:10.1016/S2213-8587(20)30160-1

23. Li W, Moore MJ, Vasilieva N, et al. Angiotensin-converting enzyme 2 is a functional receptor for the SARS coronavirus. Nature. 2003;426(6965):450-454. doi:10.1038/nature02145

24. Hoffmann M, Kleine-Weber H, Schroeder S, et al. SARS-CoV-2 cell entry depends on ACE2 and TMPRSS2 and is blocked by a clinically proven protease inhibitor. Cell. 2020;181(2):271-80.e8. doi:10.1016/ j.cell.2020.02.052 
25. Zhou P, Yang XL, Wang XG, et al. A pneumonia outbreak associated with a new coronavirus of probable bat origin. Nature. 2020;579(7798):270-273. doi:10.1038/s41586-020-20 12-7

26. $\mathrm{Xu} \mathrm{X}$, Chen $\mathrm{P}$, Wang $\mathrm{J}$, et al. Evolution of the novel coronavirus from the ongoing Wuhan outbreak and modeling of its spike protein for risk of human transmission. Sci China Life Sci. 2020;63(3):457-460. doi:10.1007/s11427-020-1637-5
27. Wernstedt Asterholm I, Tao C, Morley TS, et al. Adipocyte inflammation is essential for healthy adipose tissue expansion and remodeling. Cell Metab. 2014;20(1):103-118. doi:10.1016/j.cmet.20 14.05 .005

28. Tan L, Kang X, Ji X, et al. Validation of predictors of disease severity and outcomes in COVID-19 patients: a descriptive and retrospective study. $\operatorname{Med}$ (NY). 2020. doi:10.1016/j.medj.2020.05.002

Diabetes, Metabolic Syndrome and Obesity: Targets and Therapy

\section{Publish your work in this journal}

Diabetes, Metabolic Syndrome and Obesity: Targets and Therapy is an international, peer-reviewed open-access journal committed to the rapid publication of the latest laboratory and clinical findings in the fields of diabetes, metabolic syndrome and obesity research. Original research, review, case reports, hypothesis formation, expert opinion and commentaries are all considered for publication. The manuscript management system is completely online and includes a very quick and fair peer-review system, which is all easy to use. Visit http://www.dovepress.com/testimonials.php to read real quotes from published authors. 